\title{
Roundabout Performance Analysis Using Connected Vehicle Data
}

\author{
Enrique Saldivar-Carranza, Jijo K. Mathew, Howell Li, Darcy M. Bullock \\ Purdue University, West Lafayette, USA \\ Email: esaldiva@purdue.edu, kjijo@purdue.edu, howell-li@purdue.edu,darcy@purdue.edu
}

How to cite this paper: Saldivar-Carranza, E., Mathew, J.K., Li, H. and Bullock, D.M. (2022) Roundabout Performance Analysis Using Connected Vehicle Data. Journal of Transportation Technologies, 12, 42-58. https://doi.org/10.4236/jtts.2022.121003

Received: November 13, 2021

Accepted: December 14, 2021

Published: December 17, 2021

Copyright $\odot 2022$ by author(s) and Scientific Research Publishing Inc. This work is licensed under the Creative Commons Attribution International License (CC BY 4.0).

http://creativecommons.org/licenses/by/4.0/ (c) (i) Open Access

\begin{abstract}
There are over 8000 roundabouts in the United States. The current techniques for assessing their performance require field counts to provide inputs to analysis or simulation models. These techniques are labor-intensive and do not scale well. This paper presents a methodology to use connected vehicle (CV) trajectory data to estimate delay and level of service for roundabout approaches by adapting the Purdue Probe Diagram used for traffic signal analytics. By linear referencing vehicle trajectories with a particular movement based on the location and time they exit a roundabout, delay can be calculated. The scalability is demonstrated by applying these techniques to assess over 100 roundabouts in Carmel, IN during the weekday afternoon peak period in July 2021. Over 264,000 trajectories and 3,600,000 GPS points were analyzed to rank over 300 roundabout approaches by delay and summarize in Pareto-sorted graphics and maps. The paper concludes by discussing how these techniques can also be used to analyze queue lengths and origindestination characteristics at roundabouts. The methodology presented in this study can be used by any agency that wants to assess the performance of all roundabouts in their system.
\end{abstract}

\section{Keywords}

Roundabout, Performance Measure, Connected Vehicle, Big Data

\section{Introduction}

A roundabout is a type of circular intersection where vehicles travel around an island, it utilizes yield control for entering traffic, has channelized approaches, and implements geometries to ensure that speeds are below $30 \mathrm{mph}$ on the circulatory roadway [1]. Roundabouts have become a popular alternative to traffic signals [2]. 


\subsection{Literature Review}

Roundabout performance measures can be primarily classified into two groupssafety and operational [3]. The operational performance measures can be further divided into two sections-capacity estimations and operational characteristics including delay, level of service (LOS), and queue length.

Capacity estimations are generally associated with entrance capacity which estimates the number of vehicles that can be safely accommodated at a roundabout. There are several studies in the literature that use empirical regression models [4] [5] [6] [7] [8] and analytical gap-acceptance theories [9]-[14] to estimate roundabout capacity. The operational characteristics of roundabouts have also been widely researched. Various data sources and methods were used to study the operational performance measures: video detection [15] [16], wireless magnetometers [17] [18], Bluetooth probe data [19] [20] [21], modelling [13] [22] [23] [24] [25] and microsimulation [26]-[33].

Kyte et al. [16] performed some of the foundational research using video recording with omni-directional video cameras at 16 roundabouts in the United States to study the safety and operational impacts of roundabouts. Although this was a time-consuming and costly process, the study was able to identify queue lengths, queue duration, turning movement counts and gap sequences. The control delay at the studied roundabouts ranged from $0.0-47.1 \mathrm{sec} / \mathrm{veh}$. Kyte's study became part of a larger effort that analyzed over 300 roundabouts in the United States [3]. In another study, Flannery et al. [15] compared five two-way stop-controlled intersections that were later replaced by roundabouts and found that the sites experienced a reduction in accident frequencies, rates, and control delay. The researchers used video detection to quantify control delay as the time spent in the queue, move-up time, and service time at the head of the queue. Giuffrè et al. [34] utilized microsimulation to conclude that safety of any road unit may be measured from surrogate safety assessments.

Some studies have also used simulation to characterize the impact of connected and autonomous vehicles on the operational performance of roundabouts. Mohebifard et al. [35] evaluated the effect of various market penetration rates of connected autonomous vehicles (CAVs) on traffic operations at roundabouts using a simulation- and an optimization-based approach. The results showed that CAVs improved traffic operations in under- and semi-saturated flow conditions at $100 \%$ market penetration. Another study suggested that CAVs could provide higher throughput with lower average control delay compared to conventional vehicles' operation at roundabouts [36]. A few studies have generated vehicle trajectories or paths from aerial footage to estimate performance measures at roundabouts [37] [38].

\subsection{Motivation to Use CV Data to Assess Roundabout Performance}

The Highway Capacity Manual (HCM) defines techniques for estimating control delay, level of service, and queue length based upon demand volumes [2] [3] [8]. 
However, applying these techniques agency-wide to assess performance is labor-intensive and costly due to the extensive roundabout count data collection effort required for conducting the engineering analysis or simulation [2]. Furthermore, several papers in the literature note that local driver behavior needs to be calibrated [26] [27] [28] [29]. These requirements pose significant challenges when trying to scale the analysis. With the recent commercialization of highfidelity connected vehicle $(\mathrm{CV})$ trajectory data, practitioners can now capture system-wide coverage without instrumenting each location or making extensive field visits. $\mathrm{CV}$ data can be used to estimate operational performance of traffic controlled locations at scale [39] [40] [41].

\subsection{Objective}

The objective of this paper is to develop a methodology based on the Purdue Probe Diagram (PPD) for computing delay and LOS [42]. The PPD was originally developed for estimating control delay and LOS for signalized intersections, but those techniques can apply to roundabouts with some minor changes in locating the reference points and delay thresholds. Eliminating the need to collect turning movement counts dramatically improves the scalability of the analysis. This paper describes these techniques and demonstrates their application in Carmel, Indiana for over 100 roundabouts.

\subsection{Data}

$\mathrm{CV}$ data is used to calculate delay, LOS, queue lengths, and origin-destination characteristics. The data consists of individual vehicle waypoints with latitude, longitude, the vehicle speed and heading, a timestamp, and an anonymized unique journey identifier. The data reports with a temporal frequency of three seconds and a spatial accuracy of 1.5 meters. For this study, over 264,000 unique journeys and 3.6 million waypoints are used from July 2021 weekdays from 3:00 PM to 6:00 PM.

\section{Methodology}

This section presents the methodology in four steps: 1) Estimating delay from connected vehicle trajectories; 2) Data aggregation and visualization graphics; 3) Estimating queue lengths; 4) Tabulating roundabout origin-destination characteristics.

\subsection{Trajectory-Based Roundabout Control Delay Estimation}

The HCM proposes LOS as the main performance indicator for both, interrupted and uninterrupted flows. LOS provides 6 categories (A-F) to describe traffic operations at a particular location, "A" being ideal free-flow conditions and " $F$ " being inefficient congested conditions. For the interrupted flow scenario at roundabouts, LOS is based on control delay, and its definition is shown in Table 1 [8]. 
Table 1. HCM LOS Criteria [8].

\begin{tabular}{cc}
\hline Level of Service & Average Control Delay (s/vehicle) \\
\hline A & $\leq 10$ \\
B & $>10-15$ \\
C & $>15-25$ \\
D & $>25-35$ \\
E & $>35-50$ \\
F & $>50$ \\
\hline
\end{tabular}

Control delay is the delay caused by traffic control. For a roundabout, the traffic control is performed by the roundabout itself, its markings, and its signage. Therefore, control delay at a roundabout can be estimated by calculating the difference in travel time through the studied location between a vehicle trajectory and a free-flow trajectory (FFT), which is the hypothetical trajectory of a vehicle traveling at the posted speed limit [2] [42] [43].

Recently, several papers have been published that describe how the Purdue Probe Data Diagram [39] [41] [42] [44] can be used to estimate control delay for signalized intersections using CV trajectory data. Those techniques can be readily adapted to roundabouts. From Table 1 and the estimated control delay, individual vehicle trajectories can be assigned a LOS. Figure 1(a) shows a Purdue Probe Diagram (PPD) [42] for a roundabout, which is the time-space diagram of a vehicle trajectory that follows a particular movement [45] referenced to the distance and time in which the vehicle exited the roundabout. Callouts i-vi are vehicle trajectories approaching the roundabout from the west, traveling eastbound, at Ditch Rd. and W $96^{\text {th }}$ St. color-coded by their estimated LOS. Callout vii is a FFT. Control delay can be estimated by comparing how far away a particular trajectory is from the FFT. The farther to the left a trajectory is, the greater its control delay. Callout viii is a segregation line that helps to visually separate trajectories by their LOS (in this case separating $\mathrm{E}$ and $\mathrm{F}$ trajectories).

Figure 1(a) is a subset of Figure 1(b) to illustrate the LOS concept. Figure 1(b) shows 38 trajectories sampled between 17:00 and 17:15 hours during July 12-16, 2021 at the same roundabout approach. Figure 1(b) also has a pie chart that shows the percentage of trajectories categorized with the estimated LOS. For this approach and time period, over $30 \%$ of trajectories had a LOS F, and only $8 \%$ had a LOS A.

Using geographic information system (GIS) linear referencing, roundabout PPDs such as Figure 1(b) can be systematically generated for all the approaches at a roundabout to quantify approach delay. Approach delay is defined in this study as the delay experienced by vehicles entering from the same approach regardless of exit choice. Figure 2 shows PPDs for all four approaches at Ditch Rd. and $\mathrm{W} 96^{\text {th }}$ St. during the same peak 15-min period over five days. The southbound direction of travel, callout $i$, is the most efficient approach with most of the vehicles experiencing a LOS B. On the other hand, vehicles traveling westbound, callout ii, present the highest proportion of vehicles having a LOS F. 
Level of service: $\square \mathrm{A} \square \mathrm{B} \square \mathrm{C} \square \mathrm{D} \square \mathrm{E} \square \mathrm{F}$

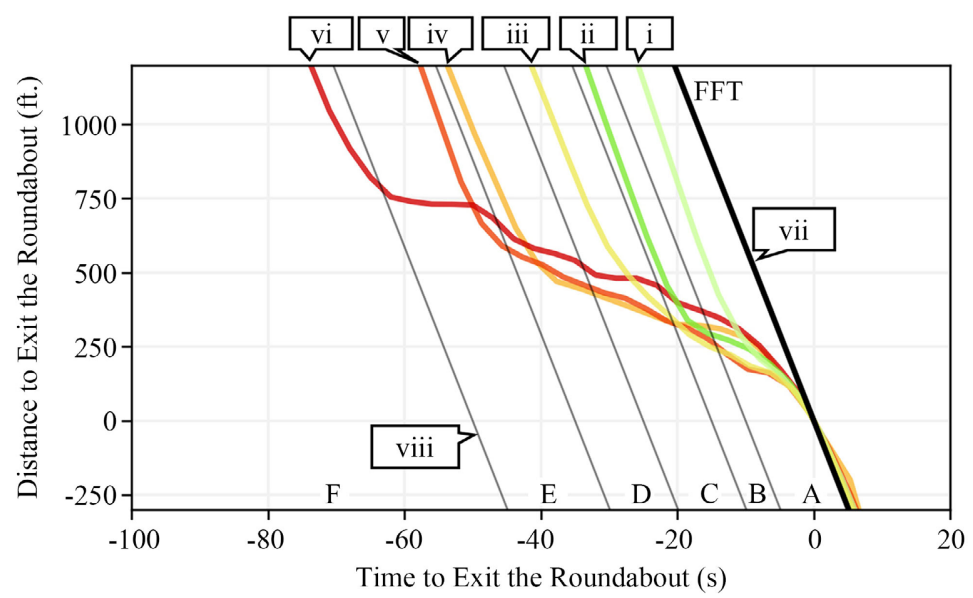

(a)

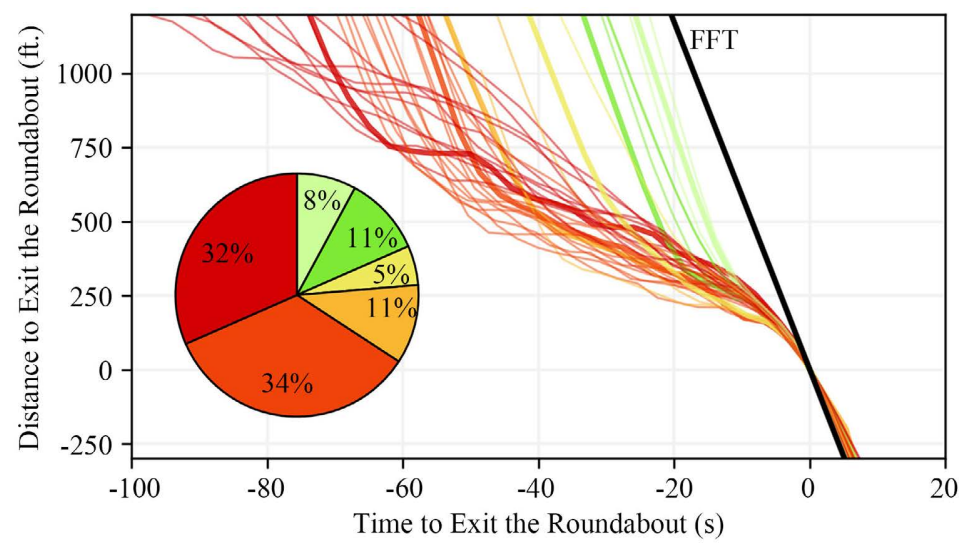

(b)

Figure 1. Vehicle trajectories approaching eastbound at Ditch Rd. and W $96^{\text {th }}$ St. during a peak 15-minute period (17:00-17:15 hrs.) between July $12^{\text {th }}-16^{\text {th }}$, 2021. (a) Trajectories with different levels of service; (b) All 38 trajectories analyzed during the time-of-day period.

By averaging the control delay experienced by each sampled vehicle over the studied approach and time period, each approach can be assigned a LOS. For the analysis shown in Figure 2, the weighted average control delay (and LOS) for the southbound (SB), westbound (WB), northbound (NB), and eastbound (EB) approaches was $16 \mathrm{sec}(\mathrm{C}), 67 \mathrm{sec}(\mathrm{F}), 41 \mathrm{sec}(\mathrm{E})$, and $44 \mathrm{sec}(\mathrm{E})$, respectively. In contrast, Figure 3 shows PPDs for all approaches at the same location during a non-peak 15-min period. In this case, the weighted average control delay (and LOS) for the SB, WB, NB, and EB approaches was $10 \mathrm{sec}(\mathrm{A}), 18 \mathrm{sec}(\mathrm{C}), 16 \mathrm{sec}$ (C), and $14 \sec (B)$, respectively.

One particularly noteworthy benefit of using $\mathrm{CV}$ data is the ability to cover most hours of the day to characterize temporal variations in performance. Figure 4 shows the LOS change by 15-minute periods for the four approaches at Ditch Rd. and W 96th St. Callout i represents the time-period and approach 
Level of service: $\square \mathrm{A} \square \mathrm{B} \square \mathrm{C} \square \mathrm{D} \square \mathrm{E} \square \mathrm{F}$

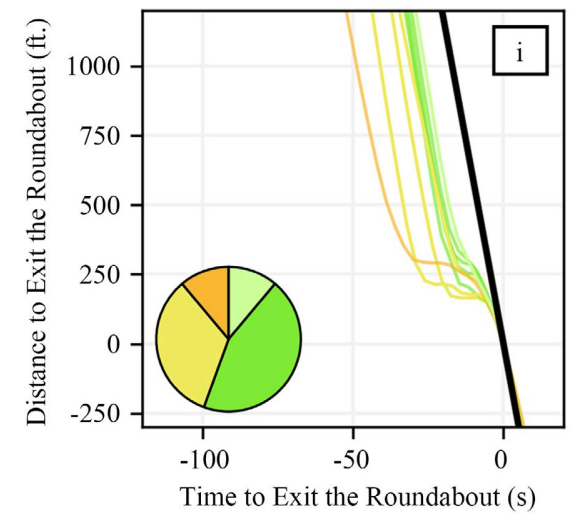

(a)

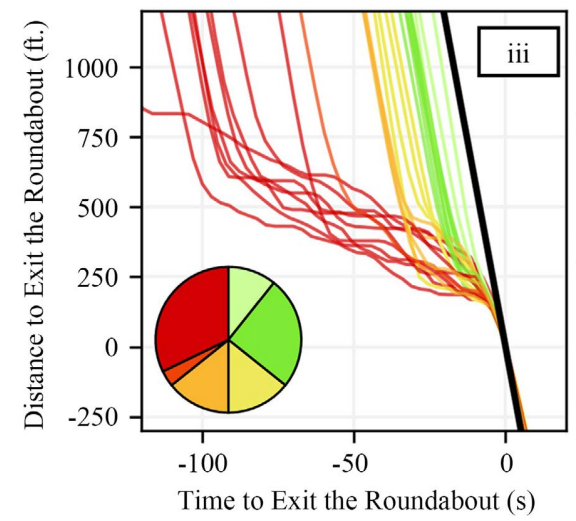

(c)

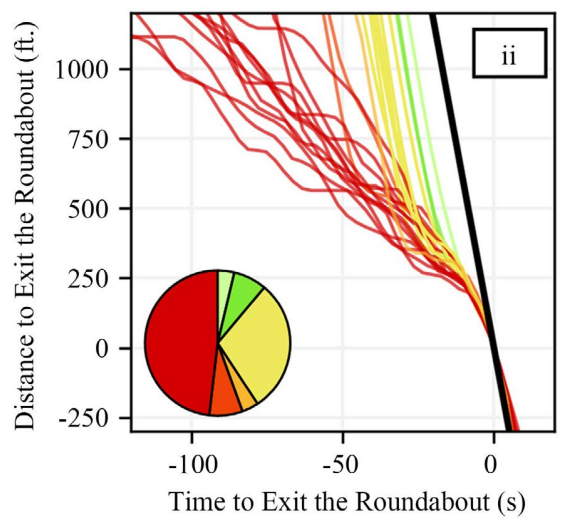

(b)

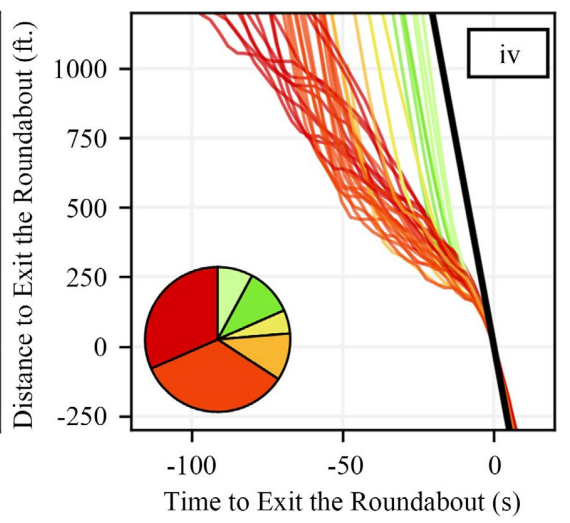

(d)

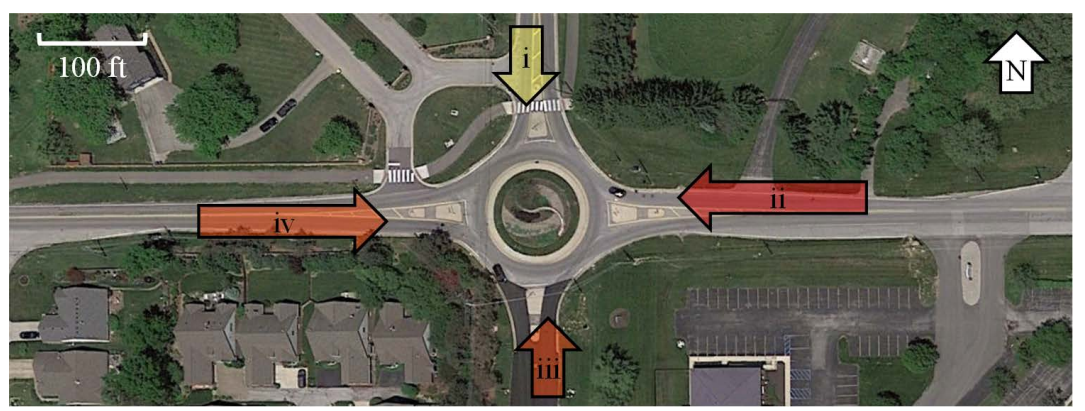

(e)

Figure 2. Ditch Rd. and $\mathrm{W} 96^{\text {th }}$ St. trajectories by approach and estimated LOS during a peak 15-minute period (17:00-17:15 hrs.) between July $12^{\text {th }}-16^{\text {th }}, 2021$. (a) Southbound PPD; (b) Westbound PPD; (c) Northbound PPD; (d) Eastbound PPD; (e) Aerial view (map data: Google, IndianaMap Framework Data, Maxar Technologies).

analyzed in Figure 1 and Figure 2(d). This visualization provides an efficient performance summary for a single location that helps identify direction of travel and time-of-day (TOD) where the roundabouts underperform.

\subsection{Data Aggregation and Visualization Graphics}

Until now, only LOS that describes the performance at individual roundabouts 
have been discussed. However, agencies are typically interested in system-wide assessment of all their approaches, as well as the weighted average of all approaches of each roundabout.

Figure 5 shows pareto-sorted bar-graphs of the average control delay by hour experienced by each approach on over 100 roundabouts in Carmel, Indiana. LOS

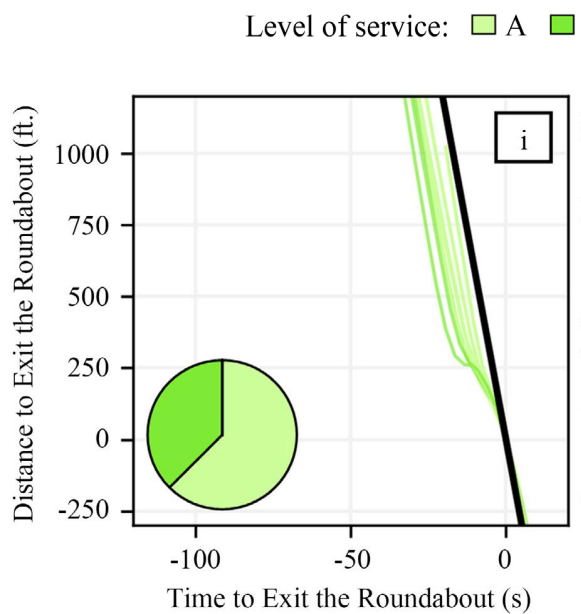

(a)

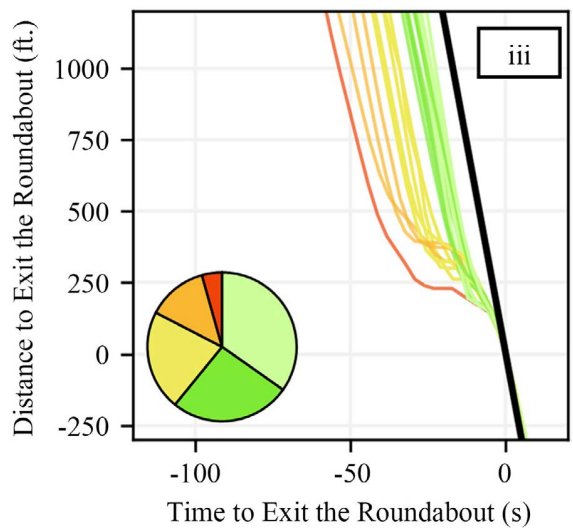

(c)

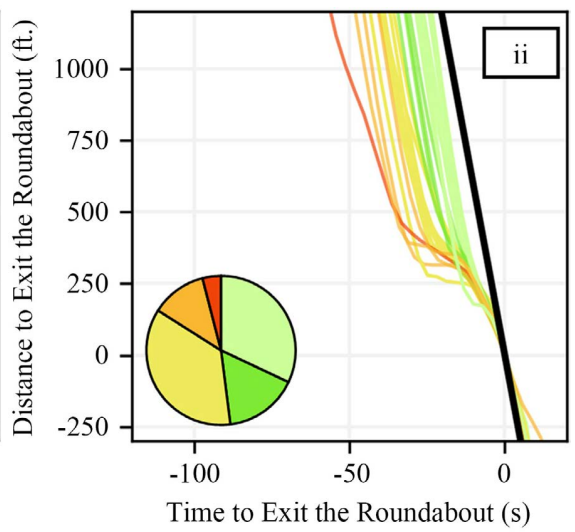

(b)

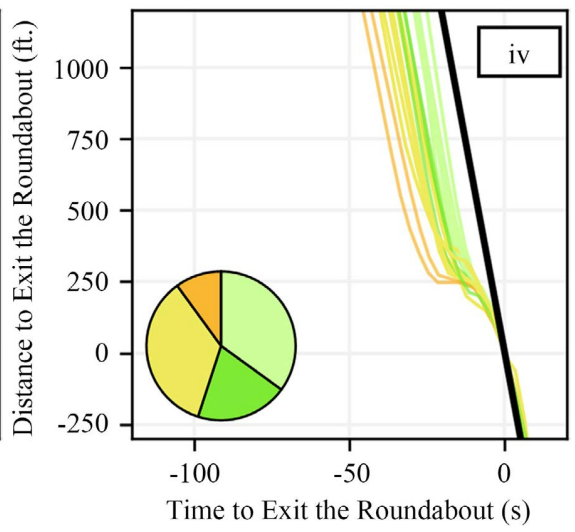

(d)

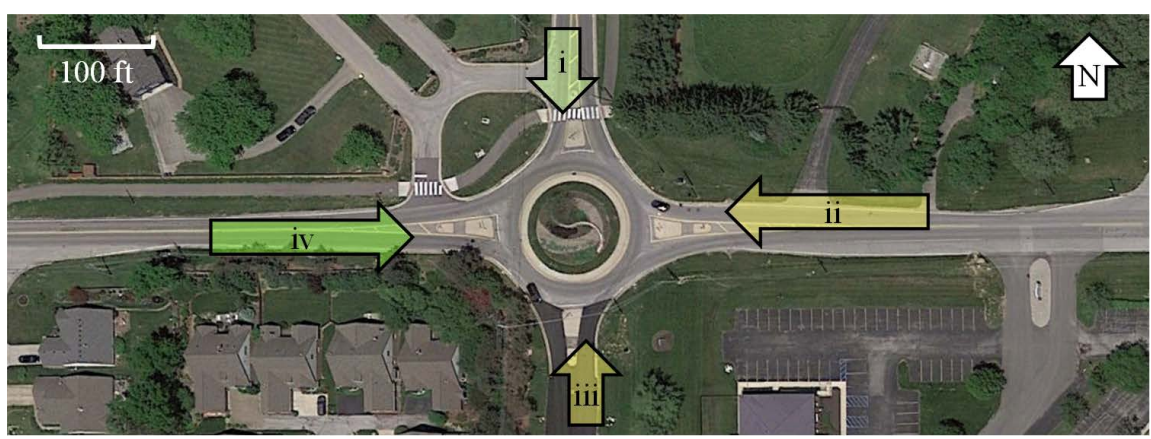

(e)

Figure 3. Ditch Rd. and W $96^{\text {th }}$ St. trajectories by approach and estimated LOS during a non-peak 15-minute period (15:00-15:15 hrs.) between July $12^{\text {th }}-16^{\text {th }}, 2021$. (a) Southbound PPD; (b) Westbound PPD; (c) Northbound PPD; (d) Eastbound PPD; (e) Aerial view (map data: Google, IndianaMap Framework Data, Maxar Technologies). 
Level of service: $\square \mathrm{A} \square \mathrm{B} \square \mathrm{C} \square \mathrm{D} \square \mathrm{E} \square \mathrm{F} \quad \square$ No Data

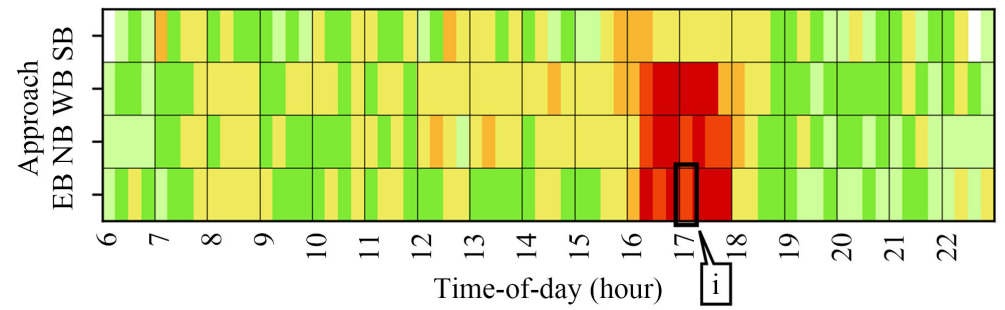

Figure 4. LOS estimation by time-of-day at Ditch $\mathrm{Rd}$. and $\mathrm{W} 96^{\text {th }}$ St. between July $12^{\text {th }}-16^{\text {th }}, 2021$.

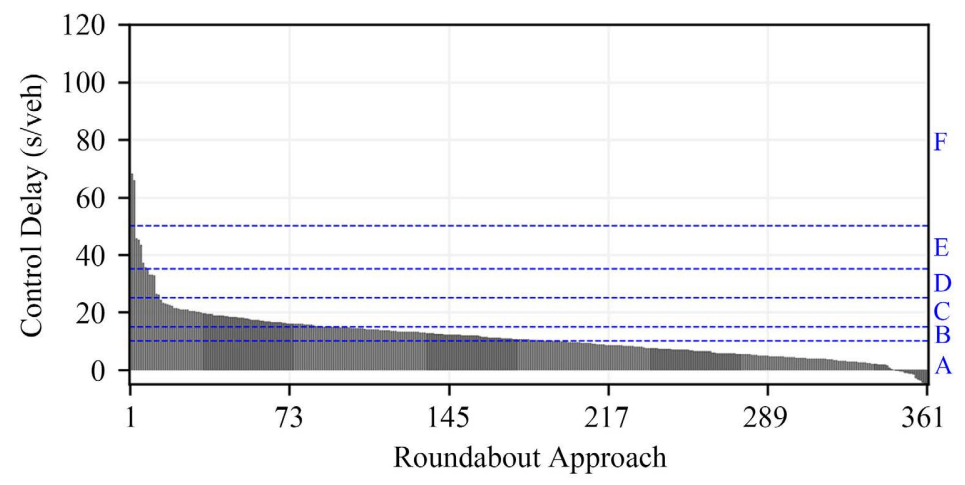

(a)

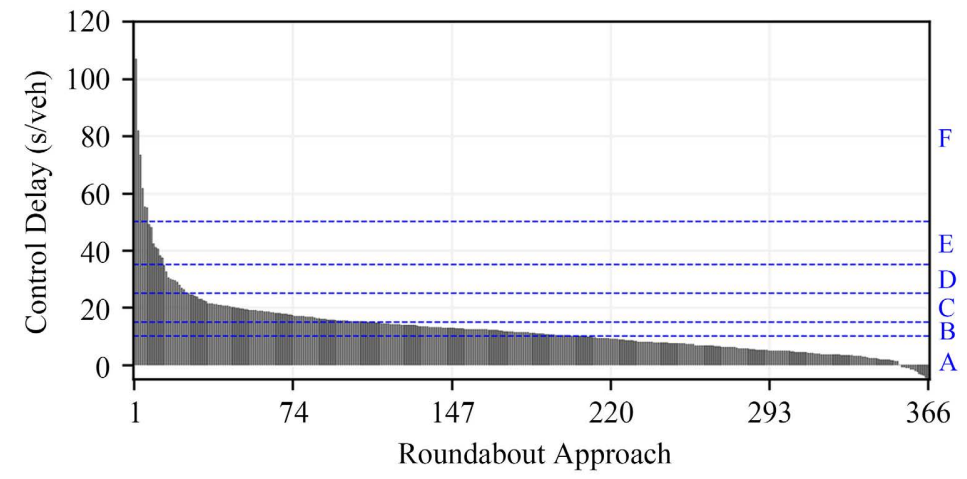

(b)

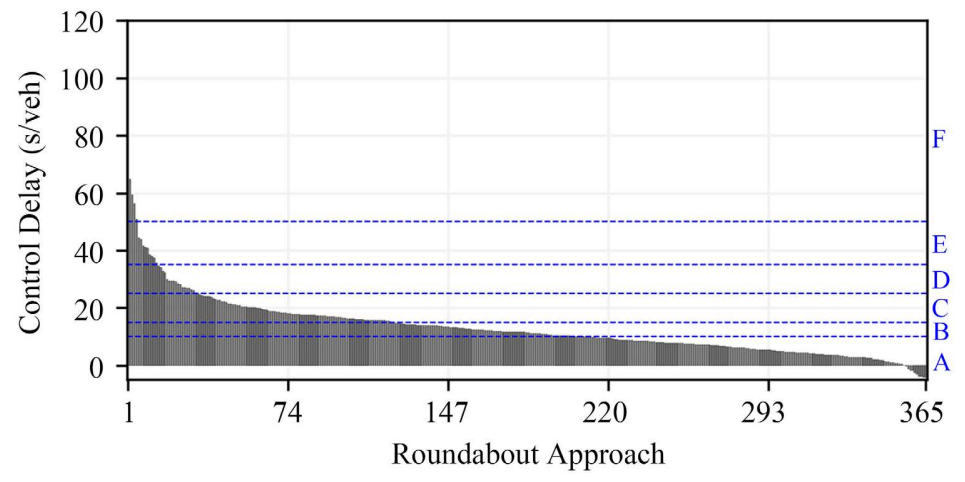

(c)

Figure 5. LOS system visualization by approach for all the weekdays in July 2021. (a) 15:00-16:00 hrs.; (b) 16:00-17:00 hrs.; (c) 17:00-18:00 hrs. 
thresholds are shown with blue lines. Only approaches with at least 10 sampled vehicles during the analysis period are considered. As demand fluctuates throughout the day, the number of approaches with 10 sampled vehicles or more also change.

These visualizations are particularly useful when assessing the quantity of approaches experiencing congestion (LOS F or E) and identifying peak periods (time with most $\mathrm{C}$ or worse LOS approaches). Additionally, locations in which vehicles travel faster than the posted speed limit (negative delay) can also be identified.

Figure 6(a) shows a Pareto-sorted bar-graph of the average control delay experienced on every approach in the system during the 15-minute period (17:00-17:15 hrs.) of the day with the most approaches with a LOS C or worse. From this graph, the locations with the highest delays can easily be identified for further analysis. Figure 6(b) shows the 10 approaches with the highest estimated control delay. Callout $i$, corresponding to the NB movement of roundabout 1 (Keystone Pkwy at $116^{\text {th }}$ St E), has a control delay of 276 seconds (the y-axis is truncated at 120 seconds).

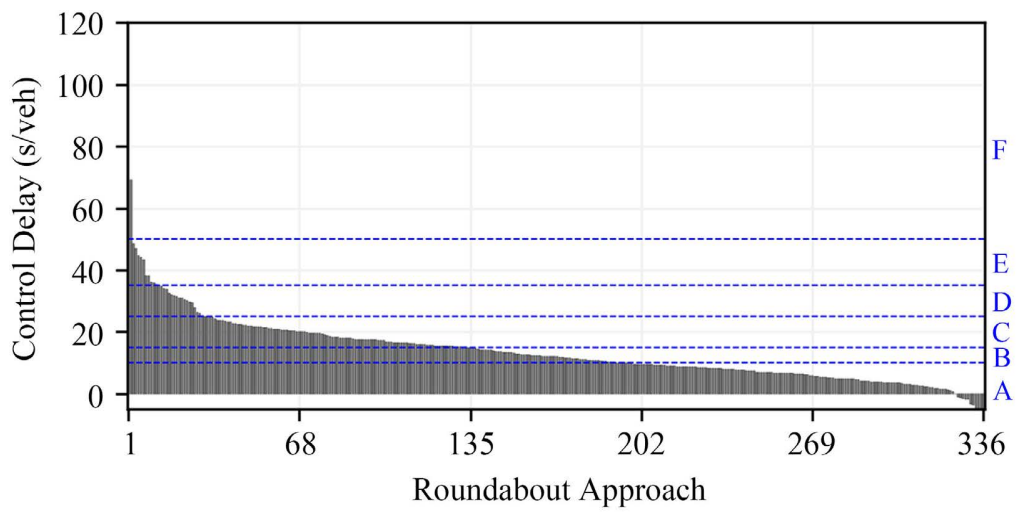

(a)

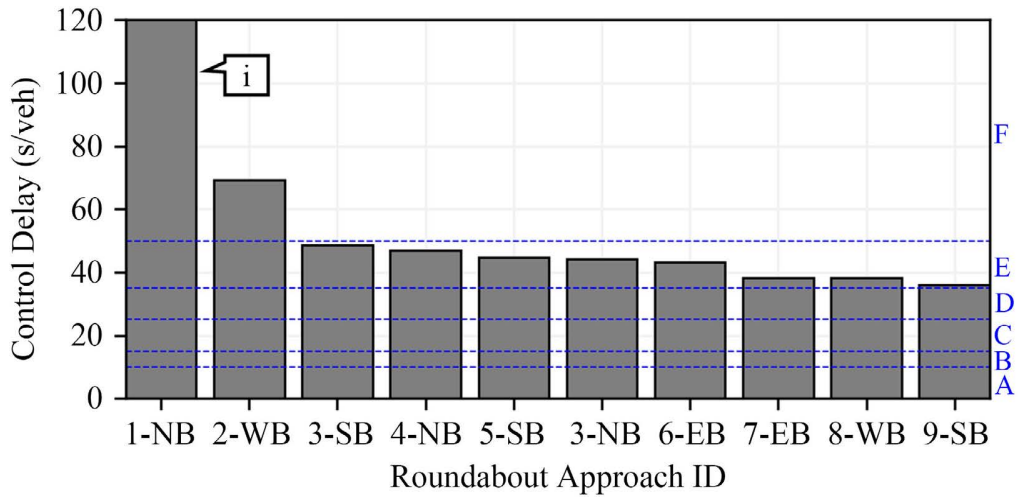

(b)

Figure 6. LOS system visualization by approach for all the weekdays in July 2021 during the most congested 15-minute period (17:00-17:15 hrs.). (a) All 336 analyzed approaches; (b) 10 highest-delays by approach with their location ID. 
A geographical representation of the results, instead of Pareto-sorted graphs, can provide practitioners with insight on the effects that certain roundabouts may have on adjacent locations. Figure 7(a) shows the analyzed roundabouts color-coded by their highest-delay approach's LOS. Callouts reference the roundabouts' ID and direction of travel (SB, EB, NB, or WB) as presented in Figure $6(b)$.

Roundabout 3 has two approaches that are within the 10 highest approach delays in the system during the study period. Vehicles coming from the west, traveling $\mathrm{EB}$, have the highest delay between all approaches at roundabouts 6 and 7. Therefore, vehicles traversing EB through these roundabouts are likely to experience significant delay at each location. Given roundabouts' 6 and 7 proximity to each other, it is possible that the poor performance at roundabout 7 is propagating to roundabout 6 . Thus, improving operational performance at $7 \mathrm{can}$ potentially benefit 6 as well.

\section{Level of service: $\square \mathrm{A} \quad \square \mathrm{B} \quad \square \mathrm{C} \square \mathrm{D} \square \mathrm{E} \quad \square \mathrm{F}$}

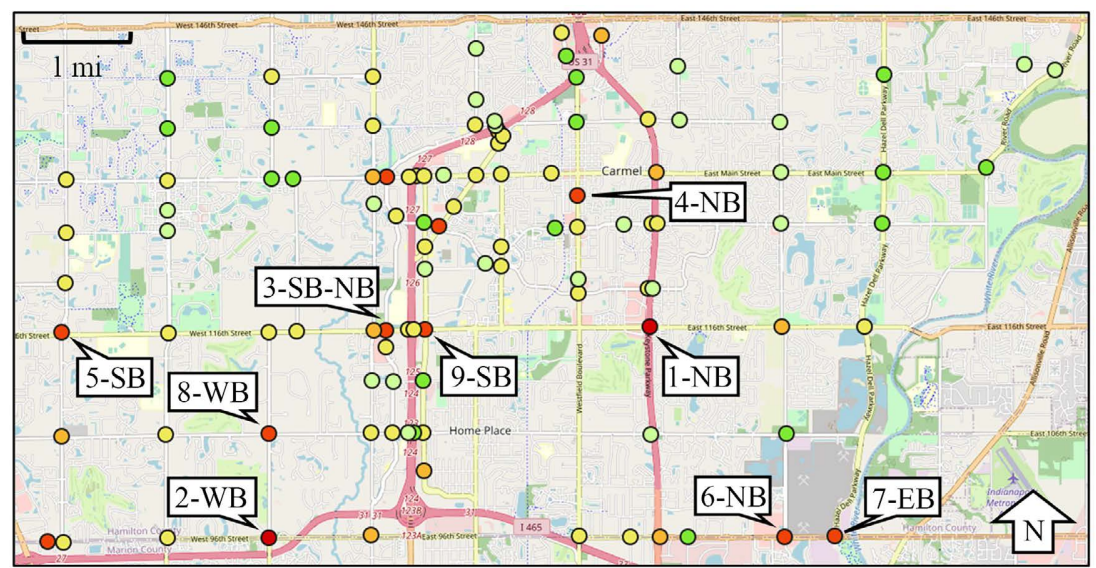

(a)

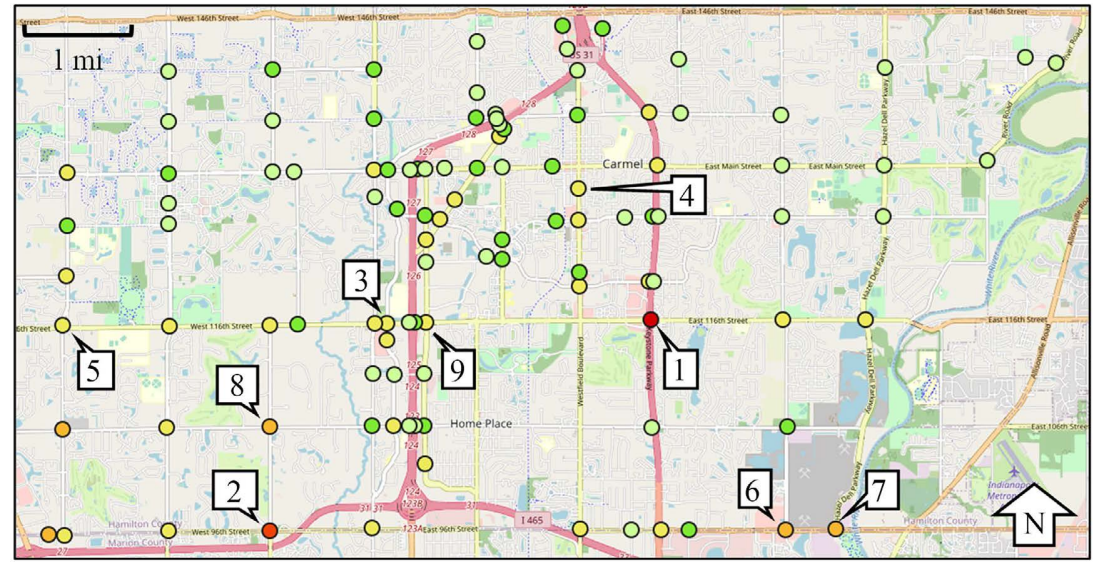

(b)

Figure 7. LOS system visualization from the 17:00 to the 17:15 hrs. for all the weekdays in July 2021 (map data: OpenStreetMap contributors, CC-BY-SA). (a) Highest delay approach; (b) Weighted average by roundabout. 
Additionally, studied locations can be color-coded by the LOS based on the weighted average control delay from all the approaches (Figure 7(b)), instead of only focusing on the highest-delay approach. With weighted average control delay, the total level of performance at a roundabout is shown, and it is calculated by dividing the total control delay of all vehicles by the number of samples. If a location has a poor LOS when based on the highest-delay approach, but a good LOS when taking into consideration all the approaches, it is an indication that few approaches in that roundabout are under-performing. In contrast, if a location shows poor LOS in both maps (Figure 7(a) and Figure 7(b)), that indicates that most of the entering vehicles have high control delay.

Table 2 shows the 10 highest estimated control delays by approach (Figure 6(b) and Figure 7(a)). Further, the weighted average, by entering volume, for the entire roundabout is also provided.

\subsection{Queue Length Estimation}

The Purdue Probe Diagram can also estimate queue length at signalized intersections based on vehicle stops and their distance from the stop bar (Figure 1). The same methodology can be also extended to estimate queue lengths for roundabout approaches [1] [8].

The HCM provides a technique to compute $95^{\text {th }}$ percentile queue lengths at roundabouts based on volume-to-capacity ratios, lane capacities, and study time periods [8]. In this study, queue length is estimated as the distance to the center of the roundabout when a vehicle first stops during its approach. The queue lengths from several days can be aggregated over various TOD periods to estimate the $95^{\text {th }}$ percentile queue length. Figure 8 shows the estimated $95^{\text {th }}$ percentile queue length, as used by the HCM [8], at Ditch Rd. and W $96^{\text {th }}$ St. from data sampled during all the weekdays in July 2021. As expected, the delay presented in Figure 4 relates to the queue length in Figure 8, since the highest delays occur during the time with the longest queues (from the 16:00 to the 18:00 hrs. for approaches $\mathrm{WB}, \mathrm{NB}$, and $\mathrm{EB})$.

Table 2. Roundabout approaches with highest control delay between 17:00 and 17:15 hrs.

\begin{tabular}{|c|c|c|c|c|c|c|}
\hline ID & Name & $\begin{array}{l}\text { NB Delay } \\
\text { (s/veh) }\end{array}$ & $\begin{array}{l}\text { EB Delay } \\
\text { (s/veh) }\end{array}$ & $\begin{array}{l}\text { SB Delay } \\
\text { (s/veh) }\end{array}$ & $\begin{array}{l}\text { WB Delay } \\
\text { (s/veh) }\end{array}$ & $\begin{array}{c}\text { Weighted Average } \\
\text { (s/veh) }\end{array}$ \\
\hline 1 & Keystone Pkwy@ 116th St E & 276 & N/A & N/A & 9 & 75 \\
\hline 2 & 96th St @ Ditch Rd & 34 & 30 & 20 & 69 & 42 \\
\hline 3 & 116th St @ Illinois St & 44 & 24 & 49 & 21 & 25 \\
\hline 4 & Rangeline Rd @ 4th St SW & 47 & 8 & 14 & N/A & 17 \\
\hline 5 & 116th St @ Shelborne Rd & 26 & 15 & 45 & 18 & 23 \\
\hline 6 & 96th@Gray Rd & 35 & 43 & 20 & 12 & 32 \\
\hline 7 & 96th @ Hazel Dell Pkwy & N/A & 38 & 20 & 9 & 27 \\
\hline 8 & 106th St @ Ditch Rd & 17 & 18 & 15 & 38 & 26 \\
\hline 9 & 116th St @ Pennsylvania St & 28 & 12 & 36 & 23 & 21 \\
\hline
\end{tabular}


$95^{\text {th }}$ Queue length (ft.):
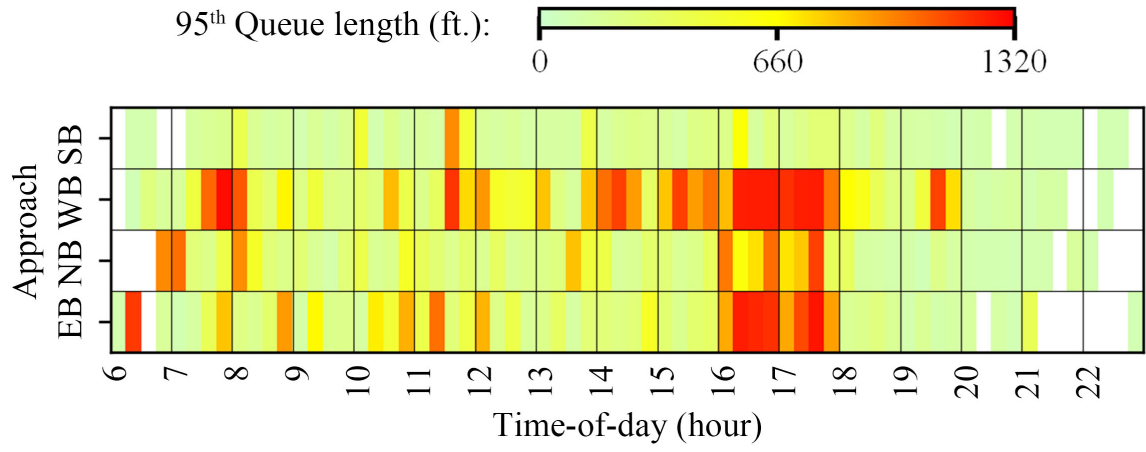

Figure 8. Estimated queue length by time-of-day at Ditch Rd. and W $96^{\text {th }}$ St. (ID 2) for weekdays in July 2021.

\subsection{Origin-Destination Characteristics}

The technique used to automatically identify vehicle turning movements from trajectory data can provide valuable information on the origin-destination characteristics at roundabouts and the variation over time [45]. Table 3 shows July 2021 weekdays vehicle turning counts at Ditch Rd. and W $96^{\text {th }}$ St. From this table, the movements with higher demands can be identified for each 15-minute segment during the AM and PM peak periods. Even though the counts shown are a sample of all the vehicles that cross through the roundabout, valuable insight can be obtained from the demand distribution that can help practitioners prioritize mitigation techniques where needed. These values can then be used to scale approach volumes to estimate absolute movement volume by time period.

Table 3. July 2021 weekdays vehicle turning counts at Ditch Rd. and W $96^{\text {th }}$ St (ID 2).

\begin{tabular}{ccccccccccccc}
\hline \multirow{2}{*}{ Start Time } & \multicolumn{3}{c}{ Southbound } & \multicolumn{3}{c}{ Westbound } & \multicolumn{3}{c}{ Northbound } & \multicolumn{3}{c}{ Eastbound } \\
\cline { 2 - 11 } & $\mathrm{L}$ & $\mathrm{T}$ & $\mathrm{R}$ & $\mathrm{L}$ & $\mathrm{T}$ & $\mathrm{R}$ & $\mathrm{L}$ & $\mathrm{T}$ & $\mathrm{R}$ & $\mathrm{L}$ & $\mathrm{T}$ & $\mathrm{R}$ \\
\hline $6: 00$ & 0 & 5 & 0 & 24 & 6 & 0 & 1 & 13 & 7 & 0 & 22 & 2 \\
$6: 15$ & 0 & 19 & 0 & 30 & 18 & 0 & 2 & 0 & 21 & 0 & 16 & 2 \\
$6: 30$ & 2 & 34 & 2 & 67 & 48 & 0 & 14 & 4 & 31 & 1 & 16 & 3 \\
$6: 45$ & 3 & 8 & 0 & 87 & 47 & 3 & 8 & 3 & 54 & 1 & 33 & 1 \\
$7: 00$ & 0 & 12 & 0 & 46 & 38 & 0 & 4 & 6 & 38 & 1 & 47 & 1 \\
$7: 15$ & 0 & 36 & 1 & 87 & 61 & 0 & 7 & 9 & 49 & 0 & 36 & 6 \\
$7: 30$ & 3 & 45 & 1 & 72 & 44 & 3 & 12 & 32 & 66 & 3 & 87 & 8 \\
$7: 45$ & 3 & 56 & 4 & 61 & 58 & 1 & 10 & 44 & 75 & 5 & 52 & 16 \\
$8: 00$ & 8 & 40 & 7 & 65 & 44 & 1 & 22 & 19 & 28 & 6 & 47 & 20 \\
$8: 15$ & 2 & 45 & 2 & 35 & 31 & 3 & 16 & 26 & 40 & 8 & 62 & 16 \\
$8: 30$ & 9 & 24 & 4 & 34 & 33 & 2 & 7 & 21 & 32 & 8 & 61 & 7 \\
$8: 45$ & 2 & 29 & 7 & 45 & 50 & 7 & 12 & 23 & 43 & 7 & 48 & 5 \\
$15: 00$ & 3 & 32 & 6 & 28 & 55 & 8 & 16 & 28 & 49 & 5 & 90 & 14 \\
$15: 15$ & 4 & 25 & 3 & 32 & 70 & 4 & 6 & 32 & 33 & 5 & 65 & 13 \\
\hline
\end{tabular}




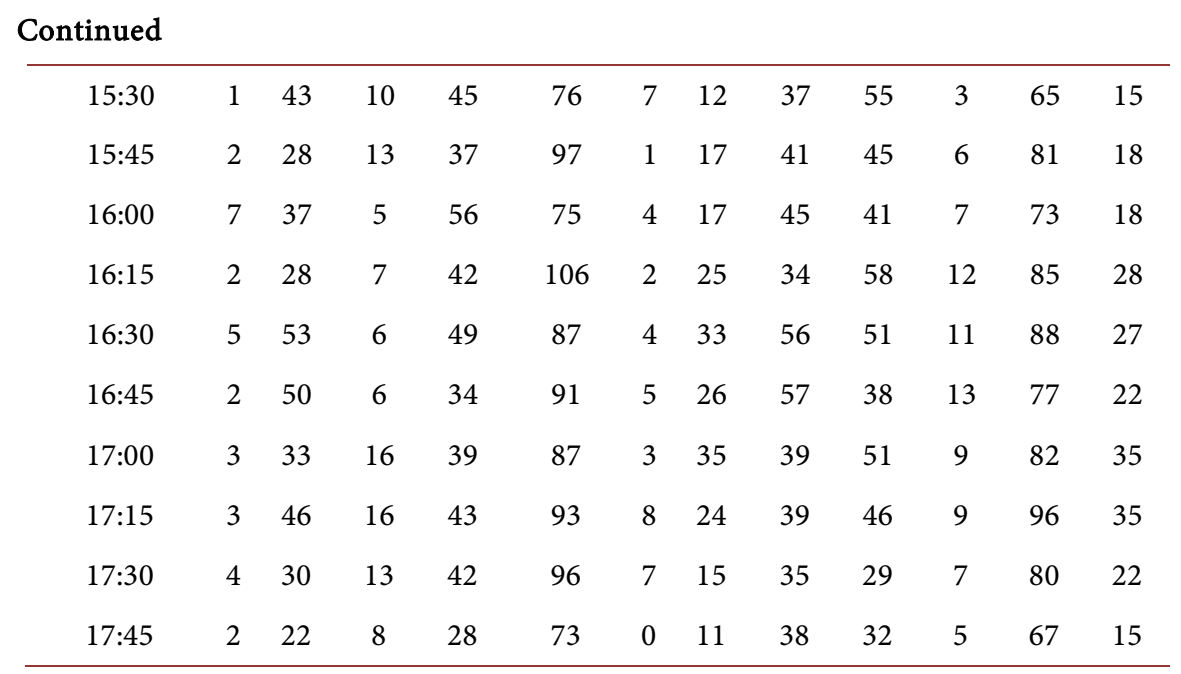

Note: $\mathrm{L}=\mathrm{Left}, \mathrm{T}=$ through, $\mathrm{R}=$ Right.

\section{Conclusions}

This study presented a methodology to use CV data with a three-second reporting interval to estimate delay, level of service, queue length, and origindestination characteristics for roundabouts. The benefit to consultants and agencies is that these techniques can be performed without any extensive and costly field data collection efforts currently required to evaluate the performance of a roundabout.

The delay and level of service techniques were based on the Purdue Probe Diagram, commonly used in traffic signal analytics (Figure 2 and Figure 3). A heatmap was used to illustrate how the control delay varies by approach and TOD (Figure 4). The scalability of this methodology was demonstrated by applying it to analyze over 100 roundabouts in Carmel, Indiana during the afternoon peak period in July 2021. Over 264,000 trajectories and 3,600,000 GPS points were analyzed during weekdays to rank over 300 roundabout approaches by delay and summarize in Pareto sorted graphics (Figure 5 and Figure 6) and maps (Figure 7). The paper concluded by illustrating how additional performance characteristics such as queue length (Figure 8) and variation in origin-destination patterns (Table 3) can be analyzed with CV data.

The techniques presented in this paper can be used to assess system-wide performance of roundabouts. Longer term, as agencies and consultants develop libraries of roundabout performance analyzed using CV data, that data can be used to improve the calibration of roundabout models and simulation models used in planning applications.

\section{Acknowledgements}

Trajectory data for July 2021 weekdays used in this study was provided by Wejo Data Services, Inc. This work was supported by the Joint Transportation Research Program. The contents of this paper reflect the views of the authors, who are responsible for the facts and the accuracy of the data presented herein, and 
do not necessarily reflect the official views or policies of the sponsoring organizations. These contents do not constitute a standard, specification, or regulation.

\section{Conflicts of Interest}

The authors declare no conflicts of interest regarding the publication of this paper.

\section{References}

[1] FHWA (2000) Roundabouts: An Informational Guide. https://www.fhwa.dot.gov/publications/research/safety/00067/00067.pdf

[2] NCHRP (2010) Roundabouts: An Informational Guide. Washington DC. https://nacto.org/docs/usdg/nchrprpt672.pdf

[3] NCHRP (2007) Roundabouts in the United States. Washington DC. https://nacto.org/docs/usdg/nchrprpt572.pdf

[4] Özuysal, M., Çalişkanelli, S.P., Tanyel, S. and Baran, T. (2009) Capacity Prediction for Traffic Circles: Applicability of ANN. Proceedings of the Institution of Civil Engineers: Transport, 162, 195-206. https://doi.org/10.1680/tran.2009.162.4.195

[5] Department of Transport (1981) TA 23/81 Junctions and Accesses-Determination of Size of Roundabouts and Major/Minor Junctions: Design Manual for Roads and Bridges. London.

[6] Ren, L., Qu, X., Guan, H., Easa, S. and Oh, E. (2016) Evaluation of Roundabout Capacity Models: An Empirical Case Study. Journal of Transportation Engineering, 142, Article ID: 04016066. https://doi.org/10.1061/(ASCE)TE.1943-5436.0000878

[7] Kimber, R.M. (1980) Traffic Capacity of Roundabouts. TRRL Laboratory Report (Transport and Road Research Laboratory, Great Britain), No. 942.

[8] Transportation Research Board (TRB) (2010) Highway Capacity Manual 2010. National Research Council (NRC), Washington DC.

[9] Dahl, J. and Lee, C. (2012) Empirical Estimation of Capacity for Roundabouts Using Adjusted Gap-Acceptance Parameters for Trucks. Transportation Research Record, 2312, 34-45. https://doi.org/10.3141/2312-04

[10] Akçelik, R. (2003) A Roundabout Case Study Comparing Capacity Estimates from Alternative Analytical Models. 2nd Urban Street Symposium, Anaheim, 28-30 July 2003, 1-19.

[11] Akcelik, R. (2007) A Review of Gap-Acceptance Capacity Models. The 29th Conference of Australian Institutes of Transport Research (CAITR 2007), Adelaide, 5-7 December 2007, 1-25.

[12] Xu, F. and Tian, Z.Z. (2008) Driver Behavior and Gap-Acceptance Characteristics at Roundabouts in California. Transportation Research Record, 2071, 117-124. https://doi.org/10.3141/2071-14

[13] Akçelik, R. (1994) Gap Acceptance Modelling by Traffic Signal Analog. Traffic Engineering and Control, 35, 498-506.

[14] Transportation Research Board (TRB) (2000) Highway Capacity Manual. National Research Council (NRC), Washington DC.

[15] Flannery, A., Elefteriadou, L., Koza, P. and Mcfadden, J. (1998) Safety, Delay, and Capacity of Single-Lane Roundabouts in the United States. Transportation Research Record, 1646, 63-70. https://doi.org/10.3141/1646-08 
[16] Kyte, M., Dixon, M., List, G., Flannery, A. and Rodegerdts, L. (2005) NCRHP 3-65: Data Collection and Extraction.

[17] Hainen, A., et al. (2013) Roundabout Critical Headway Measurement Based on High-Resolution Event-Based Data from Wireless Magnetometers. Transportation Research Record, 2389, 51-64. https://doi.org/10.3141/2389-06

[18] Hainen, A. (2016) Investigating Mixed Logit Analysis of Critical Headways at a Single-Lane Instrumented Roundabout. Journal of the Transportation Research Forum, 55, 83-96. https://doi.org/10.5399/osu/jtrf.55.3.4391

[19] Day, C., Hainen, A. and Bullock, D. (2013) Best Practices for Roundabouts on State Highways. No. FHWA/IN/JTRP-2013/14. Joint Transportation Research Program, Indiana Department of Transportation and Purdue University, 128. https://doi.org/10.5703/1288284315216

[20] Rescot, R.A. (2011) Feasibility of Bluetooth Data as a Surrogate Analysis Measure of Traffic. University of Kansas, Lawrence.

[21] Rescot, R.A. and Schrock, S.D. (2013) Estimating Turning Movements at Roundabouts Using Bluetooth Technology. Transportation Research Board 92nd Annual Meeting, Washington DC, 13-17 January 2013, 1-24.

[22] Crown, R.B. (1987) Rodel-An Alternative Approach to Roundabout Design. Highways and Transportation, 34, 12-19.

[23] Flannery, A., Kharoufeh, J.P., Gautam, N. and Elefteriadou, L. (2005) Queuing Delay Models for Single-Lane Roundabouts. Civil Engineering and Environmental Science, 22, 133-150. https://doi.org/10.1080/10286600500279949

[24] Hollis, E.M., Semmens, M.C. and Denniss, S.L. (1980) Arcady: A Computer Program to Model Capacities, Queues and Delays at Roundabouts. Wokingham, Berkshire.

[25] Hamim, O.F., Hossain, Md.S. and Hadiuzzaman, Md. (2021) Developing Empirical Model with Graphical Tool to Estimate and Predict Capacity of Rural Highway Roundabouts. International Journal of Transportation Science and Technology, 1-12. https://doi.org/10.1016/j.ijtst.2021.10.002

[26] Praticò, F.G., Vaiana, R. and Gallelli, V. (2012) Transport and Traffic Management by Micro Simulation Models: Operational Use and Performance of Roundabouts. WIT Transactions on the Built Environment, 128, 383-394. https://doi.org/10.2495/UT120331

[27] Ghanim, M., Kharbeche, M., Hannun, J., Hannun, J. and Shamiyeh, K. (2020) Safety and Operational Performance of Signalized Roundabouts: A Case Study in Doha. Procedia Computer Science, 170, 427-433. https://doi.org/10.1016/j.procs.2020.03.085

[28] Martin-Gasulla, M., Garcia, A., Moreno, A.T. and Llorca, C. (2016) Capacity and Operational Improvements of Metering Roundabouts in Spain. Transportation Research Procedia, 15, 295-307. https://doi.org/10.1016/j.trpro.2016.06.025

[29] Valdez, M., Cheu, R.L. and Duran, C. (2011) Operations of Modern Roundabout with Unbalanced Approach Volumes. Transportation Research Record, 2265, 234-243. https://doi.org/10.3141/2265-26

[30] Mohebifard, R. and Hajbabaie, A. (2021) Trajectory Control in Roundabouts with a Mixed Fleet of Automated and Human-Driven Vehicles. Computer-Aided Civil and Infrastructure Engineering, 1-19. https://doi.org/10.1111/mice.12711

[31] Mohebifard, R. and Hajbabaie, A. (2021) Connected Automated Vehicle Control in Single Lane Roundabouts. Transportation Research Part C: Emerging Technologies, 
131, 1-22. https://doi.org/10.1016/j.trc.2021.103308

[32] Owais, M., Abulwafa, O. and Abbas, Y.A. (2020) When to Decide to Convert a Roundabout to a Signalized Intersection: Simulation Approach for Case Studies in Jeddah and Al-Madinah. Arabian Journal for Science and Engineering, 45, 78977914. https://doi.org/10.1007/s13369-020-04479-6

[33] Giuffrè, T., Trubia, S., Canale, A. and Persaud, B. (2017) Using Microsimulation to Evaluate Safety and Operational Implications of Newer Roundabout Layouts for European Road Networks. Sustainability, 9, 1-13. https://doi.org/10.3390/su9112084

[34] Giuffrè, O., et al. (2018) Evaluation of Roundabout Safety Performance through Surrogate Safety Measures from Microsimulation. Journal of Advanced Transportation, 2018, Article ID: 4915970. https://doi.org/10.1155/2018/4915970

[35] Mohebifard, R. and Hajbabaie, A. (2020) Effects of Automated Vehicles on Traffic Operations at Roundabouts. 2020 IEEE 23rd International Conference on Intelligent Transportation Systems (ITSC), Rhodes, 20-23 September 2020, 1-6. https://doi.org/10.1109/ITSC45102.2020.9294563

[36] Martin-Gasulla, M. and Elefteriadou, L. (2021) Traffic Management with Autonomous and Connected Vehicles at Single-Lane Roundabouts. Transportation Research Part C: Emerging Technologies, 125, Article ID: 102964.

https://doi.org/10.1016/j.trc.2021.102964

[37] Bassani, M. and Mussone, L. (2020) Experimental Analysis of Operational Data for Roundabouts through Advanced Image Processing. Journal of Traffic and Transportation Engineering (English Edition), 7, 482-497.

https://doi.org/10.1016/j.jtte.2019.01.005

[38] Khan, M.A., et al. (2018) Unmanned Aerial Vehicle-Based Traffic Analysis: A Case Study to Analyze Traffic Streams at Urban Roundabouts. Procedia Computer Science, 130, 636-643. https://doi.org/10.1016/j.procs.2018.04.114

[39] Saldivar-Carranza, E.D., Hunter, M., Li, H., Mathew, J. and Bullock, D.M. (2021) Longitudinal Performance Assessment of Traffic Signal System Impacted by LongTerm Interstate Construction Diversion Using Connected Vehicle Data. Journal of Transportation Technologies, 11, 644-659. https://doi.org/10.4236/jtts.2021.114040

[40] Desai, J., Saldivar-carranza, E., Mathew, J.K., Li, H., Platte, T. and Bullock, D. (2021) Methodology for Applying Connected Vehicle Data to Evaluate Impact of Interstate Construction Work Zone Diversions. 2021 IEEE International Intelligent Transportation Systems Conference (ITSC), Indianapolis, 19-22 September 2021, 4035-4042. https://doi.org/10.1109/ITSC48978.2021.9564873

[41] Saldivar-Carranza, E.D., Li, H. and Bullock, D.M. (2021) Diverging Diamond Interchange Performance Measures Using Connected Vehicle Data. Journal of Transportation Technologies, 11, 628-643. https://doi.org/10.4236/jtts.2021.114039

[42] Saldivar-Carranza, E., Li, H., Mathew, J., Hunter, M., Sturdevant, J. and Bullock, D. (2021) Deriving Operational Traffic Signal Performance Measures from Vehicle Trajectory Data. Transportation Research Record: Journal of the Transportation Research Board, 2675, 1250-1264. https://doi.org/10.1177/03611981211006725

[43] Quiroga, C. and Bullock, D. (1999) Measuring Control Delay at Signalized Intersections. Journal of Transportation Engineering, 125, 271-280. https://doi.org/10.1061/(ASCE)0733-947X(1999)125:4(271)

[44] Saldivar-Carranza, E.D., Mathew, J.K., Li, H., Hunter, M., Platte, T. and Bullock, D.M. (2021) Using Connected Vehicle Data to Evaluate Traffic Signal Performance and Driver Behavior after Changing Left-Turns Phasing. 2021 IEEE International 
Intelligent Transportation Systems Conference (ITSC), Indianapolis, 19-22 September 2021, 4028-4034. https://doi.org/10.1109/ITSC48978.2021.9564654

[45] Saldivar-Carranza, E.D., Li, H. and Bullock, D.M. (2021) Identifying Vehicle Turning Movements at Intersections from Trajectory Data. 2021 IEEE International Intelligent Transportation Systems Conference (ITSC), Indianapolis, 19-22 September 2021, 4043-4050. https://doi.org/10.1109/ITSC48978.2021.9564781 